\title{
Manajemen Persediaan dengan Metode ABC, Hierarchical Clustering, dan EOQ Untuk Menentukan Reorder Point
}

\author{
Aditya Bagus Wicaksana ${ }^{1}$, M Amin Syukron ${ }^{2}$, Melinska Ayu Febrianti ${ }^{1}$, Qurtubi ${ }^{1 *}$ \\ ${ }^{1}$ Jurusan Teknik Industri \\ Universitas Islam Indonesia, Jalan Kaliurang Km 14.5 Sleman, D.I. Yogyakarta \\ ${ }^{2}$ Magister Teknik Industri \\ Universitas Islam Indonesia, Jalan Kaliurang Km 14.5 Sleman, D.I. Yogyakarta \\ *email: qurtubi@uii.ac.id \\ doi: https://doi.org/10.31315/opsi.v13i2.3998
}

Received: $21^{\text {st }}$ September 2020; Revised: $22^{\text {nd }}$ October 2020; Accepted: $27^{\text {th }}$ November 2020;

Available online: $22^{\text {nd }}$ December 2020; Published regularly: December 2020

\begin{abstract}
PT XYZ is a company that produces various types of laundry machine with variety of capacity. It is important for a company to maintain the quality of production. The large number of different components originated from several suppliers scattered in several locations, require proper planning to avoid lack of parts or excessive of parts stored in the warehouse. The method of Activity Based Costing (ABC) and Hierarchical Clustering are employed to determine products and main components that are prioritized, as well as to perform reorder point calculation for product's main components. The result of research identifies five raw materials that should be prioritized and considered, which are Old Version Rad Radiator, As VCN D $50 \mathrm{~mm}$ (Length of $60 \mathrm{~cm}$ ) Black PlatEser MS $1 \mathrm{~mm}$, Motor 1 HP 3 Phase 4 pole B3 Toshiba, and Steam trap S31N Miyawaki 1.6 MPA 220 Degree $15 \mathrm{~mm} \mathrm{1/2".} \mathrm{Reorder} \mathrm{point} \mathrm{for} \mathrm{old} \mathrm{radiator} \mathrm{could} \mathrm{be} \mathrm{carried} \mathrm{out} \mathrm{on} \mathrm{the} 4^{\text {th }}$ day with safety stock of 2 units. Maximum storage is determined for 6 units with EOQ of 4 units.
\end{abstract}

Keywords: ABC Method; EOQ; Hierarchical Clustering; Raw Material

\begin{abstract}
ABSTRAK
PT XYZ merupakan perusahaan yang memproduksi segala mesin laundry dengan berbagai ukuran kapasitas. Penting bagi perusahaan untuk mempertahankan kualitas barang produksi. Banyaknya barang penyusun yang berasal dari pemasok di berbagai tempat membuat perlu dilakukannya perencanaan agar tidak terjadi kekosongan part atau terlalu banyak part pada gudang. Metode Activity Based Costing (ABC) dan Hierarchical Clustering digunakan untuk menentukan produk dan bahan penyusun utama yang perlu diprioritaskan serta melakukan perhitungan reorder point untuk bahan penyusun utama produk. Hasil penelitian mendapatkan bahwa diketahui 5 bahan baku yang diutamakan dan diperhatikan, yaitu Rad Radiator Versi Lama, As VCN d $50 \mathrm{~mm}$ (Pjg $60 \mathrm{~cm}$ ), PlatEser Hitam MS 1 mm, Motor 1 HP 3 Phase 4 pole B3 Toshiba, dan Steam trap S31N Miyawaki 1.6 MPA 220 Derajad $15 \mathrm{~mm} \mathrm{1/2"} \mathrm{dengan} \mathrm{reorder} \mathrm{point} \mathrm{radiator} \mathrm{lama} \mathrm{dilakukan} \mathrm{pada} \mathrm{hari} \mathrm{keempat} \mathrm{dengan} \mathrm{nilai}$ safety stock sejumlah 2 unit dan maksimal penyimpanan 6 unit dengan EOQ 4 unit.
\end{abstract}

Kata Kunci: Bahan Baku; EOQ; Hierarchical Clustering; Metode ABC; Produk

\section{PENDAHULUAN}

PT XYZ merupakan perusahaan yang bergerak di bidang manufaktur. Perusahaan ini memproduksi segala mesin laundry dengan berbagai ukuran kapasitas. Oleh karena itu terdapat tanggung jawab yang dimiliki oleh perusahaan ini guna mempertahankan kualitas serta meningkatkan kualitas barang yang diproduksi. Barang-barang penyusun berasal dari beberapa pemasok yang berasal dari berbagai tempat. Bahan penyusun setiap produk memiliki sekitar 50-100 part, sehingga perlu dilakukan manajemen persediaan atau perencanaan pengendalian persediaan bahan baku. Tujuan dari pengendalian persediaan bahan baku adalah untuk menekan biaya-biaya operasional seminimal mungkin sehingga kinerja dan keuntungan perusahaan lebih optimal (Lahu, 2017). Menurut Riyanto (2012), dibandingkan dengan kebutuhan, investasi persediaan yang terlalu besar perlu menambah biaya bunga, menambah biaya penyimpanan dan pemeliharaan gudang, serta memperbesar 
kemungkinan kerugian akibat kerusakan, kemunduran, dan keusangan. Semua ini akan mengurangi keuntungan perusahaan. Demikian pula di sisi lain, karena persediaan tidak mencukupi, investasi persediaan yang terlalu sedikit akan mempengaruhi laba, karena perusahaan tidak dapat bekerja di area produksi yang optimal.

Perusahaan ini menjual variasi produk yang sangat banyak. Terdapat 8 produk utama, antara lain Dryer, Washer Extractor, Roll Ironer, Exctractor, Washer Capsule, Siyuba Dryer, Spinner Carpet, dan Vaccum Table. Setiap produk memiliki produk turunan dengan total 53 produk turunan. Terdapat 2 jenis produk Washer, antara lain Washer Extractor dan Washer Capsule dengan berbagai ukuran, mulai dari berkapasitas $20 \mathrm{~kg}$ hingga $120 \mathrm{Kg}$. Produk Washer terdiri dari 11 jenis. Extractor terdiri dari 3 jenis dengan ukuran berkapasitas $20 \mathrm{~kg}$, $40 \mathrm{~kg}$, dan $80 \mathrm{~kg}$. Dryer terdiri dari 3 jenis, yaitu LPG, listrik dan steam dengan berbagai ukuran mulai dari yang berkapasitas $16 \mathrm{~kg}$ sampai dengan $120 \mathrm{~kg}$ dan total produk sebanyak 26 jenis. Roll Ironer terdiri dari 3 jenis yang sama dengan Dryer. Variasi ukuran terdiri dari $120 \mathrm{~cm}$ hingga $317 \mathrm{~cm}$ dengan total produk Roll Ironer sebanyak 11 produk.

Manajemen persediaan telah mengatur bahwa penanganan persediaan yang bersifat probabilistik dapat dilakukan dengan cara menentukan tingkat persediaan pengaman (safety stock) dan tingkat pemesanan kembali (reorder point) (Hudori, 2018). Dalam mengatur safety stock agar selalu sesuai dengan kebutuhan produksi dan mengurangi biaya gudang diperlukan tindakan pengaturan titik untuk melakukan pemesanan barang kembali (reorder point). Sebelum menentukan reorder point akan dilakukan analisa produk prioritas dengan menggunakan metode $\mathrm{ABC}$ dan metode Hierarchical Clustering.

Metode ABC digunakan karena akan membandingkan produk utama yang berjumlah 8 dan antar produk yang berjumlah 53 produk. ABC dapat dijadikan sebagai sistem yang pertama kali menelusuri biaya pada kegiatan/aktivitas kemudian pada produk (Hansen, 2009). Horngren (2009) mendefinisikan $\mathrm{ABC}$ sebagai suatu sistem pendekatan perhitungan biaya yang dilakukan berdasarkan aktivitas yang ada di perusahaan. Premis dari sistem tersebut adalah aktivitas yang dilakukan di perusahaan merupakan penyebab biaya, sehingga wajar jika alokasi overhead didasarkan pada aktivitas tersebut (Suratinoyo, 2013). Acuan dasar yang digunakan peneliti untuk metode $\mathrm{ABC}$ adalah omset yang diterima perusahaan dari penjualan masing-masing produk. Metode ABC menggunakan 2 pembanding, yakni produk utama serta produk turunan dari produk utama, dan perbandingan omset langsung 53 produk yang dijual. Hal ini dilakukan agar dapat diketahui produk utama yang paling disukai dan produk turunan yang paling disukai pelanggan.

Setelah didapatkan output dari metode tersebut akan dilakukan clustering bahan penyusun dari produk yang paling laku. Metode Hierarchical Clustering digunakan dalam hal ini dengan pertimbangan beberapa kriteria, antara lain total harga, lot size pembelian, lead time pemesanan, dan nilai kelayakan pemasok. Metode ini digunakan untuk mengetahui urutan kluster penyusun produk dari Metode $\mathrm{ABC}$ di mana dari 53 produk menjadi 1 produk utama. Selanjutnya dapat dilakukan perhitungan reorder point dari kluster yang diutamakan. Reorder point menggunakan data demand dan lead time bahan penyusun. Hasil dari metodemetode tersebut digunakan sebagai rekomendasi untuk melakukan pembelian titik kembali bahan penyusun produk utama.

\section{METODE PENELITIAN}

\subsection{Pengumpulan Data}

Lokasi PT XYZ berada di Yogyakarta, Indonesia. Pengumpulan data dilakukan pada tanggal 1 Februari - 1 Maret 2020. Observasi dan wawancara merupakan teknik pengambilan data yang dilakukan. Observasi dilakukan dengan melihat secara langsung alur proses produksi, mesin dan peralatan yang digunakan, dan alur produk dari raw material hingga menjadi finish goods. Sementara itu, wawancara dilakukan kepada supervisor produksi dan departemen continuous improvement untuk mendapatkan info dan batasan data yang data diperoleh. Wawancara juga dilakukan untuk menyesuaikan informasi yang didapat di lantai produksi dengan tujuan yang diinginkan sebenarnya.

\subsection{Metode ABC}

Metode Activity Based Costing (ABC) merupakan penyediaan informasi yang disajikan secara lengkap berisi pengelolaan aktivitas yang tergabung di dalam sistem informasi biaya. 
Sistem informasi digunakan untuk basis pengurangan biaya dan penentuan secara akurat biaya produk atau jasa sebagai tujuan (Mulyadi, 2015)

\subsection{Hierarchical Clustering}

Analisis klaster merupakan kelas teknik yang dipergunakan untuk mengklasifikasi objek atau kasus (responden) ke dalam kelompok yang relatif homogen atau disebut klaster. Objek dalam setiap kelompok cenderung mirip satu sama lain dan berbeda jauh (tidak sama) dengan objek dari klaster lainnya (Supranto, 2004).

Metode Aglomerative Hierarchical Clustering (Klaster Hirarki Aglomerativ) ini memulai pengelompokan dengan dua atau lebih objek yang mempunyai kesamaan paling dekat. Kemudian proses diteruskan ke objek lain yang mempunyai kedekatan kedua. Demikian seterusnya sehingga klaster akan membentuk semacam "pohon", di mana ada hierarki (tingkatan) yang jelas antar objek dari yang paling mirip sampai paling tidak mirip. Secara logika semua objek pada akhirnya akan membentuk sebuah klaster. Dendrogram biasanya digunakan untuk membantu memperjelas proses hierarki tersebut.

\subsection{Reorder Point}

Menurut Heizer dan Render (2006), reorder point adalah titik pemesanan ulang adalah tingkat atau titik persediaan di mana tindakan harus diambil untuk mengisi kembali persediaan barang. Ada beberapa faktor yang mempengaruhi ROP antara lain, lead time, tingkat pemakaian bahan baku rata-rata per satuan waktu tertentu, dan safety stock. Beberapa literatur telah mengusulkan cara menentukan safety stock dan reorder point, tetapi hanya dibatasi dalam kondisi tertentu. Russel dan Taylor (2011) hanya memformulasikan untuk kondisi demand yang bervariasi dan lead time yang tetap.

\section{HASIL DAN PEMBAHASAN}

\subsection{Metode ABC 8 Produk Utama}

Berdasarkan hasil perhitungan Metode ABC pada 8 jenis produk utama yaitu Dryer, Washer Extractor, Roll Ironer, Extractor,
Washer Capsule, Siyuba Dryer, Spinner Carpet dan Vaccum Tabble. Dryer memiliki penjualan sejumlah 18 unit dengan total omset Rp1.696.855.023 sejumlah 37,4\% dari total penjualan. Produk Washer Extractor memiliki total penjualan 7 unit dengan total omset Rp1.684.980.000 sejumlah $37,2 \%$ dari total penjualan. Roll Ironer memiliki omset Rp448.111.537 dengan penjualan 3 unit dan persentase penjualan 9,89. Extractor sejumlah 3 unit terjual dengan omset Rp376.615.800 dan persentase $8,31 \%$. Washer Capsule memiliki penjualan 2 unit dengan omset Rp254.265.000 persentase 5,61\%. Siyuba Dryer memiliki penjualan 4 unit dengan omset Rp68.000.000 dan persentase 1,5\%. Produk Dryer, Washer Extractor, dan Roll Ironner masuk dalam klasifikasi kelompok A. Setelah dilakukan metode $\mathrm{ABC}$ pada produk, langkah selanjutnya menghitung produk turunan dari produk penjualan tertinggi yaitu Dryer. Produk Dryer memiliki 12 macam produk turunan dengan berbagai ukuran dan sistem pemanas, yaitu ukuran $16 \mathrm{~kg}, 30 \mathrm{~kg}, 40 \mathrm{~kg}, 50 \mathrm{~kg}, 60 \mathrm{~kg}, 80 \mathrm{~kg}$, $90 \mathrm{~kg}, 100 \mathrm{~kg}, 120 \mathrm{~kg}$ dengan sistem pemanas steam, LPG, dan listrik. Dryer $40 \mathrm{~kg}$ Steam memiliki penjualan sejumlah 4 unit dengan omset Rp541.716.000 dengan persentase 31,9\%, kemudian produk Dryer $40 \mathrm{~kg}$ LPG dengan penjualan sejumlah 3 unit dan omset Rp298.287.000 serta persentase 17\%. Hasil dari perhitungan ini akan dibandingkan dengan metode $\mathrm{ABC}$ keseluruhan produk secara langsung.

\subsection{Metode ABC Keseluruhan Produk}

Berdasarkan hasil perhitungan metode $\mathrm{ABC}$ keseluruhan produk terdapat 10 produk yang masuk ke dalam klasifikasi kelompok A, 5 Produk masuk ke dalam kelompok B dan 1 Produk masuk ke dalam kelompok C. Produk yang termasuk ke dalam kelompok A adalah Washer Extractor $20 \mathrm{~kg}$ dengan penjualan 5 unit dan memiliki harga/unit Rp212.520.000, serta omset sejumlah Rp1.062.600.000 dengan persentase terhadap omset total sebesar $23 \%$. Dryer $40 \mathrm{~kg}$ Steam dengan penjualan 4 unit memiliki harga/unit Rp135.429.000, omset sejumlah Rp541.716.000 dengan persentase terhadap omset total sebesar 12\%. Extractor 40 $\mathrm{kg}$ dengan harga unit Rp125.538.600 dengan omset total Rp376.615.800 persentase 8\%. Hasil dari perhitungan metode $\mathrm{ABC}$ secara keseluruhan dan metode Hierarchical 
Clustering memiliki perbedaan, yaitu pada keseluruhan nilai omset terbesar adalah Washer Exctractor $20 \mathrm{~kg}$, sedangkan produk Dryer pada urutan kedua, yaitu produk Dryer $40 \mathrm{~kg}$ Steam. Dengan hasil ini yang digunakan untuk mencari Reorder Point adalah Washer Extractor $20 \mathrm{~kg}$.

\subsection{Metode ABC Kelompok Bahan Baku}

Berdasarkan hasil perhitungan metode $\mathrm{ABC}$ bahan baku terdapat 23 bahan baku yang masuk ke dalam klasifikasi kelompok A, 43 bahan baku masuk ke dalam kelompok B dan 70 bahan baku ke dalam kelompok C. Bahan baku yang termasuk ke dalam kelompok A, antara lain Radiator Versi Lama, As VCN d $50 \mathrm{~mm}$, PlatEser Hitam MS $1 \mathrm{~mm}$, Steam Trap S31N Miyawaki 1.6, Motor 1 HP 3 Phase 4Pole B3, Motor 0,5 HP 3 Phase Tsohiba, Selenoid Valve Steam $1 / 2$ " Kitz dan lainnya. Bahan baku yang masuk ke dalam kelompok B adalah Timer H3CR A8 AC100-240V, Kontaktor ST-12 220 V, PlatEser Hitam MS $3 \mathrm{~mm}$ dan 40 bahan baku lainnya. Bahan Baku yang masuk ke dalam kelompok C, antara lain As Drat / long drat M 14, Knee 1/2" Galvanis, Sock 3/4" Galvanis, dan masih 67 bahan baku lainnya. Radiator Versi Lama menjadi bahan baku yang paling mengeluarkan biaya banyak dengan kuantitas 1 , standar biaya Rp5.000.000 dan total biaya Rp5.000.000 dengan persentase 16\%. Kemudian bahan baku kedua adalah AS VCN d $50 \mathrm{~mm}$ (pjg $60 \mathrm{~cm}$ ) dengan kuantitas 1 biaya sejumlah Rp2.560.000 persentase 8\%, setelah itu ada bahan baku PlatEser Hitam MS $1 \mathrm{~mm}$ dengan kuantitas 8 unit dengan biaya per unit Rp318.500 total biaya adalah Rp2.548.000 persentase kumulatif adalah $8 \%$, kemudian banyak bahan baku lainnya hingga menghasilkan kumulatif $80 \%$, kemudian Klasifikasi kelompok B adalah produk yang menghasilkan kumulatif dari 85\% hingga 97\%, yaitu mulai dari bahan baku Timer H3CR A8 AC100-240V dengan 2 unit, harga unit Rp185.000 dengan total harga Rp370.000, Kontraktor ST-12 220V Mitsubishi dengan total kebutuhan 2 unit harga satuan Rp177.500 degan total harga Rp355.000, PlatEser Hitam MS 3 $\mathrm{mm}$ dengan kebutuhan 0,5 unit dengan harga unit Rp696.960 total kebutuhan Rp348.480.

\subsection{Metode Hierarcical Clustering}

Metode Hierarchical Clustering digunakan untuk mengetahui bahan baku masuk ke dalam kluster A, B atau C. Kluster digunakan dengan pendekatan total harga, lot size, lead time dan nilai dari pemasok. Setiap faktor memiliki penilaian tersendiri, seperti total harga mencari yang tertinggi, kemudian lot size mencari yang mendekati 1, kemudian lead time pengiriman barang yang tercepat, dan penilaian pemasok yang terbaik atau bernilai 4. Tabel 1. merupakan hasil perhitungan hierarchical clustering.

Berdasarkan Tabel 1. dapat diketahui ratarata pada masing-masing cluster yang dapat diinterpretasikan sebagai berikut.

Klaster 1: Memiliki anggota 5 bahan baku utama, di mana klaster pertama memiliki total harga tertinggi Rp1.929.940, lot size pembelian bernilai 0,866 , lead time bernilai 1,8 hari, dan nilai pemasok 3,8. Sehingga kelompok bahan baku yang di dalam klaster ini termasuk dalam Bahan Baku Perlu diperhatikan karena memiliki nilai harga tinggi kedua sehingga perlu diperhatikan pengeluarannya, lot size 0,86 dan lead time 1,8 hari hingga pemasok bernilai 3,8. 2.

Klaster 2: Memiliki anggota 125 bahan baku utama, di mana klaster kedua memiliki total harga tertinggi Rp126.541, lot size pembelian bernilai 3,508, lead time bernilai 1,72 hari, dan nilai pemasok 3,784 . Sehingga kelompok bahan baku yang di dalam klaster ini termasuk dalam Bahan Baku kurang diperhatikan karena memiliki nilai harga rendah, lot size 3,50 dan lead time 1,72 hari hingga pemasok terbaik.

Klaster 3: Memiliki anggota 5 bahan baku utama, di mana klaster ketiga memiliki total harga tertinggi Rp5.000.000, lot size pembelian bernilai 1, lead time bernilai 3 hari, dan nilai pemasok 4 (maksimum). Sehingga kelompok bahan baku yang di dalam klaster 4 ini termasuk dalam Bahan Baku Perlu sangat diperhatikan karena memiliki nilai harga tinggi, lot size 1 dan lead time 3 hari hingga pemasok terbaik. Lead time 3 hari diperhatikan juga karena ketersediaan barang yang lebih mudah didapatkan. 
Tabel 1. Hasil Perhitungan Hierarchical Clustering (Sumber: Wicaksana, 2020)

\begin{tabular}{ccccc}
\hline \multirow{2}{*}{ Klaster } & \multicolumn{4}{c}{ Rata-rata } \\
\cline { 2 - 5 } & Total harga (Tertinggi) & $\begin{array}{c}\text { Lot Size } \\
\text { (Mendekati 1 } \\
\text { Paling Baik) }\end{array}$ & $\begin{array}{c}\text { Lead Time } \\
\text { (Tercepat) }\end{array}$ & $\begin{array}{c}\text { Pemasok } \\
\text { (Terbaik) }\end{array}$ \\
\hline 3 & Rp5.000.000 & 1 & 3 & 4 \\
1 & Rp1.929.940 & 0,866 & 1,8 & 3,8 \\
2 & Rp126.541,4381 & 3,508292 & 1,72 & 1,784 \\
\hline
\end{tabular}

\subsection{Perbandingan Hasil Metode ABC dan} Hierarchical Clustering

Berdasarkan hasil perhitungan Metode ABC dan Hierarchical Clustering, dengan metode $\mathrm{ABC} 6$ urutan teratas dan metode Hierarchical Clistering dengan kluster 1 dan 3 dapat diketahui hasil seperti Tabel 2. Peneliti mengambil 5 bahan baku utama yang dijadikan untuk perhitungan Reorder Point dikarenakan memiliki kesamaan pada hasil yaitu Radiator Versi Lama, As VCN D $50 \mathrm{~mm}($ Pjg $60 \mathrm{~cm})$, PlatEser Hitam MS $1 \mathrm{~mm}$, Motor 1 HP 3 Phase 4 pole B3 Toshiba, dan Steam trap S31N Miyawaki 1.6 MPA 220 Derajad 15 mm 1/2”.

Tabel 2. Hasil Perbandingan Metode $\mathrm{ABC}$ dan Hierarchical Clustering (Sumber: Wicaksana, 2020)

\begin{tabular}{|c|c|c|}
\hline o & Metode ABC & $\begin{array}{l}\text { Hierarchical } \\
\text { Clustering }\end{array}$ \\
\hline 1 & $\begin{array}{l}\text { Radiator } \\
\text { Lama }\end{array}$ & Radiator Versi Lama \\
\hline 2 & $\begin{array}{l}\text { As VCN d } 50 \mathrm{~mm} \\
(\text { pjg } 60 \mathrm{~cm})\end{array}$ & $\begin{array}{l}\text { As VCN d 50mm (pjg } \\
60 \mathrm{~cm})\end{array}$ \\
\hline 3 & $\begin{array}{l}\text { PlatEser Hitam MS } \\
1 \mathrm{~mm}\end{array}$ & $\begin{array}{l}\text { PlatEser Hitam MS } 1 \\
\text { mm }\end{array}$ \\
\hline 4 & $\begin{array}{l}\text { Steam trap S31N } \\
\text { Miyawaki } 1.6 \mathrm{MPA} \\
220 \text { derajad } 15 \mathrm{~mm} / \\
1 / 2^{\prime \prime}\end{array}$ & $\begin{array}{l}\text { Motor 0,5 HP } 3 \text { Phase } \\
\text { Toshiba }\end{array}$ \\
\hline 5 & $\begin{array}{l}\text { Motor } 1 \text { HP } 3 \text { Phase } \\
\text { 4Pole B3 Toshiba }\end{array}$ & $\begin{array}{l}\text { Motor } 1 \text { HP } 3 \text { Phase } \\
\text { 4Pole B3 TOSHIBA }\end{array}$ \\
\hline 6 & $\begin{array}{l}\text { As Bulat MS } 10 \\
\mathrm{~mm}\end{array}$ & $\begin{array}{l}\text { Steam trap S31N } \\
\text { Miyawaki 1.6 MPA } \\
220 \text { derajad } 15 \mathrm{~mm} / \\
1 / 2^{\prime \prime}\end{array}$ \\
\hline
\end{tabular}

\subsection{Reorder Point}

Berdasarkan hasil perhitungan Reorder Point menggunakan Economic Order Quantity (EOQ), ditemukan bahwa Reorder Point atau pembelian kembali barang Radiator Lama dilakukan pada hari keempat dengan nilai safety stock sejumlah 2 unit dan maksimal penyimpanan 6 unit dengan EOQ 4 unit. Kemudian As VCN d $50 \mathrm{~mm}$ pembelian kembali dilakukan pada hari kelima dengan nilai safety stock sejumlah 2 unit dan maksimal penyimpanan 8 unit dengan EOQ 7 unit. Bahan baku selanjutnya adalah PlatEser Hitam MS 1 mm pembelian kembali barang Plat Eser Hitam MS $1 \mathrm{~mm}$ dilakukan pada hari ketujuh dengan nilai safety stock sejumlah 4 unit dan maksimal penyimpanan 10 unit dengan EOQ 7 unit. Kemudian, Motor 1 HP 3 Phase 4Pole B3 TOSHIBA pembelian kembali dilakukan pada hari kelima dengan nilai safety stock sejumlah 2 unit dan maksimal penyimpanan 8 unit dengan EOQ 6 unit. Bahan baku terakhir adalah Steam trap S31N Miyawaki 1.6 MPA pembelian kembali barang dilakukan pada hari kelima dengan nilai safety stock sejumlah 2 unit dan maksimal penyimpanan 8 unit dengan EOQ 6 unit.

\section{KESIMPULAN}

Berdasarkan hasil analisis metode $\mathrm{ABC}$ dengan pendekatan per produk dan keseluruhan produk dapat diketahui bahwa produk terlaris adalah produk Dryer $40 \mathrm{~kg}$ Steam dengan nilai omset 541 juta rupiah dan produk Washer Extractor $20 \mathrm{Kg}$ dengan omset 1 Milyar lebih 60 juta. Selain itu, dengan menggunakan metode ABC dan Hierarchical Clustering dapat diketahui 5 bahan baku yang harus diutamakan dan diperhatikan, antara lain Radiator Versi Lama, As VCN D $50 \mathrm{~mm}$ (Pjg $60 \mathrm{~cm}$ ), PlatEser Hitam MS $1 \mathrm{~mm}$, Motor 1 HP 3 Phase 4 pole B3 Toshiba dan Steam trap S31N Miyawaki 1.6 MPA 220 Derajad 15 mm 1/2”.

Reorder Point atau pembelian kembali barang Radiator Lama dilakukan pada hari keempat dengan nilai safety stock sejumlah 2 unit dan maksimal penyimpanan 6 unit dengan EOQ 4 unit. Kemudian As VCN d $50 \mathrm{~mm}$ pembelian kembali dilakukan pada hari kelima dengan nilai safety stock sejumlah 2 unit dan 
maksimal penyimpanan 8 unit dengan EOQ 7 unit. Bahan baku selanjutnya adalah PlatEser Hitam MS $1 \mathrm{~mm}$ pembelian kembali barang PlatEser Hitam MS $1 \mathrm{~mm}$ dilakukan pada hari ketujuh dengan nilai safety stock sejumlah 4 unit dan maksimal penyimpanan 10 unit dengan EOQ 7 unit. Kemudian, Motor 1 HP 3 Phase 4Pole B3 TOSHIBA pembelian kembali dilakukan pada hari kelima dengan nilai safety stock sejumlah 2 unit dan maksimal penyimpanan 8 unit dengan EOQ 6 unit. Bahan baku terakhir adalah Steam trap S31N Miyawaki 1.6 MPA pembelian kembali barang dilakukan pada hari kelima dengan nilai safety stock sejumlah 2 unit dan maksimal penyimpanan 8 unit dengan EOQ 6 unit.

\section{DAFTAR PUSTAKA}

Heizer, J., \& Rander, B. (2006). Operation Management. Jakarta: Salemba Empat.

Hansen, D. R., \& Mowen, M. M. (2009). Akuntansi Manajerial. Jakarta: Penerbit Salemba Empat.

Horngren, C. T. (2009). Pengantar Akuntansi Manajemen. Jakarta: Salemba Empat.

Hudori, M. (2018). Formulasi Model Safety Stock dan Reorder Point untuk Berbagai Kondisi Persediaan Material. Jurnal Citra Widya Edukasi, 10(3), 217-224.

Lahu, E. P., \& Sumarauw, J. S. (2017). Analisis Pengendalian Persediaan Bahan Baku Guna Meminimalkan Biaya Persediaan Pada Dunkin Donuts Manado. Jurnal EMBA: Jurnal Riset Ekonomi, Manajemen, Bisnis dan Akuntansi, 5(3).

Mulyadi. (2015). Akuntansi Biaya. Yogyakarta: Sekolah Tinggi Ilmu Manajemen YKPN.

Riyanto, B. (2012). Dasar-dasar Pembelanjaan Perusahaan. Yogyakarta: BPFE.

Russel, R.S., \& Taylor, B.W. (2011). Operations Management. USA: John Wiley \& Sons, Inc.

Supranto, J. (2004). Analisis Multivariat, Arti dan Interpretasi. Jakarta: PT. Rineka Cipta.

Suratinoyo, A. W. (2013). Penerapan sistem $\mathrm{ABC}$ untuk penentuan harga pokok produksi pada Bangun Wenang Beverage. Jurnal EMBA: Jurnal Riset Ekonomi, Manajemen, Bisnis dan Akuntansi, 1(3).

Wicaksana, A.B. (2020). Laporan Kerja Praktek. Jurusan Teknik Industri, Universitas Islam Indonesia. 